\title{
Avaliação da política pública na gestão de recursos naturais renováveis no Estado do Paraná: impactos econômicos e ambientais
}

\author{
Evaluation in public policy on renewable natural resources \\ management in Paraná State: economic and environmental impacts
}

\author{
Zung Che Yee ${ }^{1 *}$; Ricardo Ralisch ${ }^{2}$
}

\begin{abstract}
Resumo
O trabalho objetivou avaliar a eficiência na gestão de recursos naturais renováveis no Estado do Paraná na abordagem de impactos econômicos e ambientais. Baseou-se num estudo de caso em áreas com incentivos malsucedidos e fraudes não esclarecidas. A pesquisa realizada diagnosticou a estrutura fundiária e possessória do litoral paranaense, relacionando com os dados fornecidos pelo Instituto Brasileiro do Meio Ambiente e dos Recursos Naturais Renováveis - IBAMA sobre projetos de reflorestamento de palmito (Euterpe edulis Martius) na década de 1970 e com planos de cortes e manejos concedidos. Os resultados apontam que as áreas pesquisadas são viciadas, com sobreposições de títulos dominiais e litígios possessórios. A análise dos planos de manejos de palmitos nativos confirmou a ineficiência, permitindo cortes nas áreas irregulares, contribuindo para a degradação da Mata Atlântica. As distorções verificadas permanecem nos dias atuais, nas aquisições das Unidades de Conservação, nos processos de reconhecimento de Reservas Particulares do Patrimônio Natural - RPPNs, na Certificação Florestal - FSC ou nos empreendimentos ambientais como de comercialização de carbono, podendo tratar-se de uma rede.
\end{abstract}

Palavras-chave: Gestão florestal, recursos naturais renováveis, palmito

\begin{abstract}
The paper's objective was to evaluate the effectiveness of renewable natural resources management in the State of Paraná, in an approach aimed at economic and environmental impacts. It was based on a case study in areas with unsuccessful incentives and unclarified frauds. The research diagnosed the land tenure and possession structure on the coast of the State of Paraná, by relating data provided by Instituto Brasileiro do Meio Ambiente e dos Recursos Naturais Renováveis - IBAMA on heart-of-palm trees (Euterpe edulis Martius) reforestation projects in the 1970's with cutting and management plans granted. The results indicate that the researched areas are vitiated, with overlappings of tenure titles and land disputes. An analysis of native heart of palm management plans confirmed ineffectiveness, as cuts were allowed in illegal areas, contributing toward Atlantic Forest degradation. The distortions verified in the study remain to the present day, in acquisitions of Conservation Units, in proceedings for the acknowledgement of Reservas Particulares do Patrimônio Natural - (RPPN - Private Natural Heritage Reserves), in Forest Certification - FSC, or in environmental ventures such as the carbon trade, and may constitute a network.
\end{abstract}

Key words: Forest management, renewable natural resources, heart-of-palm tree

\footnotetext{
1 Eng ${ }^{\mathbf{o}}$ Agrônomo, Doutorando em Agronomia na Universidade Estadual de Londrina - UEL e Eng ${ }^{\circ}$ de Segurança do Trabalho pela UFPR. Curitiba-PR. E:mail: zungcheyee @ gmail.com

2 Eng $^{\circ}$ Agrônomo, Doutor, Professor do Departamento de Agronomia da Universidade Estadual de Londrina - UEL.

* Autor para correspondência
} 


\section{Introdução}

Historicamente, as políticas públicas de gestão de recursos naturais renováveis têm sido divididas sob duas óticas distintas: comando e controle do desmatamento e incentivo ao reflorestamento. Quanto aos incentivos ao reflorestamento no Estado do Paraná, foco do presente artigo, destaca-se o denominado Programa de Incentivos Fiscais ao Florestamento e Reflorestamento - PIFPR, que consistiu no conjunto de atos normativos elaborados no período de 1965 a 1988, que instituíram e regulamentaram os incentivos florestais concedidos a essa atividade (LOPES et al., 2000).

São inexistentes as literaturas que relatam algum tipo de avaliação dos efeitos destas políticas, com exceção das menções de fraudes e plantios malsucedidos que impediram que os reflorestamentos se concretizassem (BACHA, 1995). Contudo, este estudo não especifica a natureza das fraudes citadas e nem as razões pelas quais se atribuíram os insucessos, uma vez que os reflorestamentos possuem as vistorias anuais e seqüenciais realizadas pelo órgão fiscalizador, o então Instituto Brasileiro de Desenvolvimento Florestal - IBDF, hoje assumido pelo Instituto Brasileiro do Meio Ambiente e dos Recursos Naturais Renováveis - IBAMA.

O presente artigo, portanto, relata um estudo de caso sobre a eficiência de projeto de reflorestamento de palmito (Euterpe edulis Martius) na década de 1970, no litoral paranaense, na área de Mata Atlântica, com recursos captados pela Lei n. 5.106 e Decretolei n. 1.134, que ainda geram as autorizações de manejo sustentado, visando justamente identificar as possíveis irregularidades praticadas. Objetiva-se melhor compreender os mecanismos destas irregularidades podendo contribuir com o aperfeiçoamento das políticas atualmente vigentes.

Dentre as irregularidades, as terras viciadas ou os vícios dos títulos de propriedades destas terras, têm sido utilizados para a obtenção de recursos inadequadamente desde longa data. Da mesma forma, títulos viciados de propriedades rurais têm sido adotados na constituição de garantias para parcelamento de tributos e em dação de pagamentos (YEE, 2003). O estudo sistemático e a investigação da legitimidade e legalidade de títulos dominiais (YEE, 2000), analisando a origem e a sobreposição de títulos dominiais no Estado do Paraná (YEE, 2001), podem ser uma alternativa para tais constatações.

Este estudo trás uma abordagem pioneira do tema, podendo subsidiar as políticas florestais, agrárias e ambientais a serem adotadas.

\section{Material e Métodos}

Foram avaliados os projetos que receberam recursos previstos na Lei n. 5.106 e no Decreto-lei n. 1.134, identificados seqüencialmente e diferenciados com a letra "A" ou "B", respectivamente. Para as informações obtidas neste estudo foram adotadas quatro abordagens diferentes:

Abordagem florestal - analisaram-se os dados dos projetos de reflorestamento de palmito incentivados pela Lei n. 5.106 e pelo Decreto-lei n. 1.134, segundo levantamentos oficiais do extinto IBDF, obtidos em 1997. Analisou-se também os planos de corte concedidos aos citados projetos, informação obtida em 2002, junto à Superintendência do Paraná do IBAMA, que absorveu as funções do IBDF.

Abordagem sobre a regularidade das terras elegeu-se a Comarca de Antonina, abrangendo os Municípios de Antonina e Guaraqueçaba, Paraná, para realizar um diagnóstico exploratório da sua estrutura fundiária, realizado entre 1997 e 2002, com o propósito de identificar áreas potencialmente viciadas. Nesta região se concentram $58,5 \%$ dos projetos incentivados pela Lei n. 5.106,

O primeiro estudo avaliou os litígios existentes dentro da Comarca através do levantamento das perícias judiciais de ações possessórias e indenizatórias junto às Varas Cíveis Estaduais e Federais, na região de estudo. Este estudo contemplou a história dos conflitos fundiários existentes, notadamente sobre as áreas ainda não 
demarcadas oficialmente entre os Estados do Paraná e São Paulo, situação que remonta a 1854.

O segundo tipo de levantamento consistiu no procedimento de investigação dominial da origem das terras, dentro dos municípios de estudo, com o propósito de identificar as possíveis áreas com duplicidade de documentos, visto que até no final de 2001 foram identificados em torno de 200.000ha de terras com documentações viciadas e que se encontram localizados dentro das áreas os projetos de reflorestamento citados ${ }^{3}$.

Visando racionalizar os trabalhos e verificar a eficiência do estudo sobre a legitimidade e legalidade dos títulos dominiais, através da técnica da Investigação Dominial concebido pelo Yee (2000), para identificar possíveis vícios de titularidade das terras, foram selecionados entre 2002 e 200416 projetos da Comarca de Antonina, abrangendo os Municípios de Antonina e Guaraqueçaba, o que corresponde a $15 \%$ dos projetos desta Comarca. Como se tratou de um exercício metodológico, tanto a quantidade como quais projetos propriamente dito sofreram avaliação, foi uma escolha totalmente aleatória. A única indução ocorreu na definição da Comarca de Antonina, pois foi onde houve a maior parte dos incentivos citados, com 107 projetos.

Abordagem sobre os litígios possessórios - da mesma forma e aproveitando os levantamentos no item anterior, buscou-se analisar as terras com processos de litígios possessórios, pois isto também pode acarretar em sobreposição documental e destinação de investimentos públicos em áreas inexistentes. Este levantamento foi realizado entre 1997 a 2002 através de um diagnóstico dos conflitos possessórios, a partir dos processos judiciais da Vara Cível da Comarca de Antonina, jurisdição esta que envolve os Municípios de Antonina e Guaraqueçaba e com reais possibilidades de associação com os casos de regularidade de terras também em estudo.

Abordagem sobre os manejos sustentados complementarmente, realizou-se uma coleta de informações em 2002 junto ao IBAMA, com dados de 1990 a 2002 sobre os manejos das florestas da região de estudo. Como os projetos incentivados visavam a exploração comercial das árvores implantadas, supõe-se que esta extração tenha refletido nestas autorizações. O cruzamento desta informação com as anteriores visa tornar-se uma base para as suposições possíveis.

\section{Resultados e Discussão}

\section{Abordagem florestal}

Os projetos de implantação de reflorestamentos de palmito (Euterpe edulis Martius) autorizados pelo extinto Instituto Brasileiro de Desenvolvimento Florestal - IBDF, incentivados pela Lei n. 5.106 e pelo Decreto-lei n. 1.134, ocorreram entre os anos de 1970 e 1977. Segundo os dados da pesquisa, foi autorizada no Estado do Paraná a concessão de reflorestamentos de palmiteiros no total de 138.551,18ha, dos quais 99.647,91ha através da Lei n. 5.106 e 38.903,27ha através do Decreto-lei n. 1.134.

Quanto ao número de árvores teoricamente implantadas, constatou-se que os respectivos projetos foram vistoriados, dando como a quantidade de árvores plantadas a totalidade de 728.676.237 unidades, sendo 523.962.387 sob a Lei n. 5.106 e 204.713.850 através do Decreto-lei n. 1.134.

Quanto a distribuição por Município, temos que dos 266 principais projetos concedidos, nos Municípios de Guaraqueçaba e Antonina, que integram a Comarca de Antonina, somam 57,5\% da totalidade das árvores reflorestadas.

\footnotetext{
3 Consideraram-se somente as áreas superiores de 50.000ha identificadas na pesquisa, assim distribuídas: (a) sobreposição de áreas denominada de Lafont de 114.078,47ha; (b) vícios documentais com litígios possessórios originados dos Autos n. 295/80 da Vara Cível da Comarca de Antonina-PR; e (c) vícios documentais originados da área sem definição de localização denominada Companhia União Colonial de 50.000ha, totalizando 214.898,47ha.
} 
Analisando-se os custos relatados e somando-se todos os projetos implantados e corrigindo-os ao valor do dólar americano na cotação de $\mathrm{R} \$ 2,34$ de agosto de 2005, remonta a um montante total de US\$ 47.778.250,734 (quarenta e sete milhões, setecentos e setenta e oitenta mil e duzentos e cinqüenta dólares americanas e setenta e três centavos).

Analisando-se os laudos de vistorias das áreas reflorestadas do extinto Instituto Brasileiro de Desenvolvimento Florestal - IBDF, constata-se ter havido o repasse financeiro para uma implantação de 728.676.237 árvores de palmiteiro (Euterpe edulis Martius) na região, significando dizer que a totalidade dos incentivos foi efetivamente realizada.

Já a verificação dos planos de corte junto ao IBAMA, que consistem nas autorizações de cortes dos palmitos reflorestados concedidos até agosto/ 2002 constatou, que as autorizações de corte correspondem tão somente a 8.895.981 árvores, equivalente a $1,22 \%$ da quantidade supostamente reflorestada, decorridos 32 anos após as primeiras liberações. Destaca-se que esta cultura possui com ciclo médio de 10 anos (NOGUEIRA, 1977) e ainda possibilita as regenerações naturais. Portanto, se o objetivo dos projetos era o de exploração comercial da espécie florestal, alguma incoerência há nos dados apresentados. Ou os cortes estão acontecendo sem as respectivas autorizações ou os repasses realizados não redundaram em novas florestas efetivamente. De qualquer forma, a eficiência desta política está colocada em dúvida. Se considerarmos a possibilidade de terem sido apresentados áreas com documentos em duplicidade, os planos de cortes concedidos e a serem concedidos futuramente, baseados nos projetos citados, podem tratar-se de árvores nativa e não replantadas.

A pesquisa parcial sobre os aspectos florestais que integra nessa pesquisa, com objetivos mais amplos, aqui denominados como abordagem florestal, encontra-se no trabalho já publicado pelos autores (YEE; RALISCH, 2005).

\section{Abordagem sobre a regularidade das terras}

A amostragem realizada para pesquisar os imóveis dos projetos de reflorestamento de palmito (Euterpe edulis Martius) mostrou que todas as áreas avaliadas são viciadas.

Os vícios são originários de várias fontes: (a) da ilegitimidade na transmissão da propriedade; (b) duplicação do título dominial através de uso do artifício da ação de inventário; (c) extrapolação do imóvel fora do Município de origem; e (d) problemas documentais, consistindo a área de implantação de reflorestamento é superior à área do documento de aprovação do incentivo, conforme os dados contidos na Tabela 1.

As estruturas fundiárias dos imóveis viciadas encontram-se contidos na Tabela 2, onde se concentram nas áreas tidas como próprias $(62,5 \%)$ seguidas pelas áreas arrendadas $(25,0 \%)$ e áreas em comodato $(12,5 \%)$.

\section{Abordagem sobre os litígios possessórios}

Realizando levantamento junto aos processos judiciais na Vara Cível da Comarca de Antonina, constata-se que 11 áreas incluídas nos projetos apoiados pela Lei n. 5.106 e Decreto-lei n. 1.134 encontravam-se inseridos nos litígios possessórios, conforme os dados contidos na Tabela 3.

Isto significa que nem as áreas sabidamente litigiosas foram impedidas de receberem os recursos, denotando a falta de critérios adequados na análise das solicitações.

\footnotetext{
4 Os valores dos projetos foram convertidos em dólares americanos, com base na cotação oficial de dezembro de cada ano e somados.
} 
Tabela 1. Caracterização sobre a natureza dos vícios, Municípios de Antonina e Guaraqueçaba, Estado do Paraná - Lei n. 5.106.

\begin{tabular}{ccccc}
\hline $\begin{array}{c}\text { Pesquisa } \\
\mathbf{N}^{\mathbf{0}}\end{array}$ & $\begin{array}{c}\text { Vícios na } \\
\text { ilegitimidade na } \\
\text { transmissão } \\
\text { Da propriedade }\end{array}$ & $\begin{array}{c}\text { Vícios na duplicação } \\
\text { do título dominial } \\
\text { (via inventário) }\end{array}$ & $\begin{array}{c}\text { Vícios na } \\
\text { extrapolação do } \\
\text { imóvel fora do } \\
\text { Município de origem }\end{array}$ & $\begin{array}{c}\text { Vícios documentais } \\
\text { (área de plantio } \\
\text { superior à área do } \\
\text { documento) }\end{array}$ \\
\hline A-001 & $\mathrm{X}$ & $\mathrm{X}$ & & \\
$\mathrm{A}-004$ & $\mathrm{X}$ & $\mathrm{X}$ & & \\
$\mathrm{A}-030$ & & & & \\
$\mathrm{~A}-035$ & & $\mathrm{X}$ & & \\
$\mathrm{A}-048$ & $\mathrm{X}$ & & \\
$\mathrm{A}-050$ & $\mathrm{X}$ & $\mathrm{X}$ & & \\
$\mathrm{A}-051$ & & $\mathrm{X}$ & & \\
$\mathrm{A}-052$ & & $\mathrm{X}$ & & \\
$\mathrm{A}-092$ & & & $\mathrm{X}$ & \\
$\mathrm{A}-093$ & & & $\mathrm{X}$ & \\
$\mathrm{A}-109$ & & & $\mathrm{X}$ & \\
$\mathrm{A}-110$ & & & $\mathrm{X}$ & \\
$\mathrm{A}-124$ & & & $\mathrm{X}$ & \\
$\mathrm{A}-126$ & & & & \\
$\mathrm{~A}-151$ & & & & \\
$\mathrm{~A}-163$ & & & & \\
\hline
\end{tabular}

Tabela 2. Estrutura fundiária das áreas de estudo e identificação de áreas viciadas, Municípios de Antonina e Guaraqueçaba, Estado do Paraná, BRASIL - Lei n. 5.106

\begin{tabular}{|c|c|c|c|c|c|}
\hline $\begin{array}{l}\text { Pesquisa } \\
N^{\circ}\end{array}$ & $\begin{array}{l}\text { Área projeto } \\
\text { (ha) }\end{array}$ & $\begin{array}{l}\mathrm{N}^{\circ} \text { de árvores } \\
\text { implantadas }\end{array}$ & $\begin{array}{c}\text { Área } \\
\text { Própria }\end{array}$ & $\begin{array}{c}\text { Área } \\
\text { Arrendada }\end{array}$ & $\begin{array}{c}\text { Área } \\
\text { em comodato }\end{array}$ \\
\hline A-001 & 40,00 & 200.000 & & $\mathrm{X}$ & \\
\hline A-004 & 115,00 & 575.000 & $X$ & & \\
\hline A- 030 & $2.000,00$ & 10.000 .000 & $X$ & & \\
\hline A-035 & 110,00 & 550.000 & $X$ & & \\
\hline A- 048 & $4.310,00$ & 21.550 .000 & & & $\mathrm{X}$ \\
\hline A-050 & 179,00 & 895.000 & $\mathrm{X}$ & & \\
\hline A- 051 & 90,00 & 450.000 & $X$ & & \\
\hline A-052 & $1.400,00$ & 7.000 .000 & $X$ & & \\
\hline A-092 & 183,81 & 919.050 & $X$ & & \\
\hline A-093 & 100,00 & 500.000 & & $\mathrm{X}$ & \\
\hline A-109 & $1.150,00$ & 5.750 .000 & & $\mathrm{X}$ & \\
\hline A-110 & $1.380,00$ & 6.900 .000 & $\mathrm{X}$ & & \\
\hline A-124 & 528,00 & 2.640 .000 & $X$ & & \\
\hline A-126 & $1.174,00$ & 5.870 .000 & $\mathrm{X}$ & & \\
\hline A-151 & 715,92 & 3.579 .600 & & $X$ & \\
\hline A-163 & $2.392,00$ & 11.960 .000 & & & $\mathrm{X}$ \\
\hline Total & $15.867,73$ & 79.338.650 & & & \\
\hline
\end{tabular}


Tabela 3. Áreas com conflitos possessórios segundo processos judiciais pesquisados, Municípios de Antonina e Guaraqueçaba, Estado do Paraná - BRASIL - Lei n. 5.106 e Decreto-lei n. 1.134

\begin{tabular}{|c|c|c|c|c|c|}
\hline Legislação & $\begin{array}{c}\text { Pesquisa } \\
\mathbf{N}^{\circ}\end{array}$ & Área (ha) & $\begin{array}{c}\mathrm{N}^{0} \text { de } \\
\text { árvores }\end{array}$ & $\begin{array}{l}\text { Ano do plano } \\
\text { de corte }\end{array}$ & $\begin{array}{l}\mathrm{N}^{\circ} \text { árvores } \\
\text { autorizadas } \\
\text { para corte }\end{array}$ \\
\hline Lei n. 5.106 & A-121 & $4.698,00$ & 23.490 .000 & $\begin{array}{l}1995 \\
1999\end{array}$ & $\begin{array}{r}863.806 \\
90.000\end{array}$ \\
\hline Lei n. 5.106 & A-122 & $2.472,00$ & 12.360 .000 & 2000 & 57.925 \\
\hline Lei n. 5.106 & A-125 & $2.348,00$ & 11.740 .000 & 1987 & $\begin{array}{r}\text { Dado não } \\
\text { disponível }\end{array}$ \\
\hline Lei n. 5.106 & A-165 & $2.749,00$ & 13.745 .000 & - & 0 \\
\hline Decreto-lei n. 1.134 & B-015 & 500,00 & 2.500 .000 & 1985 & $\begin{array}{r}\text { Dado não } \\
\text { disponível }\end{array}$ \\
\hline Decreto-lei n. 1.134 & B-016 & 970,00 & 4.875 .000 & - & 0 \\
\hline Decreto-lei n. 1.134 & B-017 & 265,00 & 1.325 .000 & - & 0 \\
\hline Decreto-lei n. 1.134 & B-018 & 100,00 & 500.000 & - & 0 \\
\hline Decreto-lei n. 1.134 & B-019 & 162,00 & 810.000 & - & 0 \\
\hline Decreto-lei n. 1.134 & B- 020 & 130,00 & 650.000 & - & 0 \\
\hline Decreto-lei n. 1.134 & B-021 & 100,00 & 500.000 & - & 0 \\
\hline Total & & $14.494,00$ & 72.495 .000 & - & 1.011.731 \\
\hline
\end{tabular}

Dos 107 projetos analisados sob o amparo da Lei n. 5.106 dentro da Comarca de Antonina constatouse, através de cruzamento informações da pesquisa da estrutura fundiária dos Municípios estudados respectivamente, 13 e 23 projetos que se encontra em área de sobreposição de títulos dominiais, conforme os dados contidos nas Tabelas 4 e 5.
Isto pode demonstrar o uso de um expediente de multiplicação de título das áreas de terras que abrangem os 2 municípios, registrando-o em ambos e gerando 2 títulos. Ambos os títulos podem ter sido apresentados para pleitear os recursos de incentivos de reflorestamento, o que pode explicar a deficiência de planos de corte, pois na verdade muitas destas áreas não existem.

Tabela 4. Projetos de reflorestamento implantados em áreas de superposição de títulos dominiais

\begin{tabular}{|c|c|c|c|c|c|}
\hline $\begin{array}{c}\text { Pesquisa } \\
\mathbf{N}^{\mathbf{0}}\end{array}$ & Área (ha) & $\begin{array}{l}\mathbf{N}^{0} \text { de } \\
\text { árvores }\end{array}$ & $\begin{array}{c}\text { Denominação } \\
\text { da área }\end{array}$ & Gleba de origem & $\begin{array}{c}\text { Gleba em } \\
\text { sobreposicão }\end{array}$ \\
\hline A-001 & 40,00 & 200.000 & & Lafont $^{2}$ & Lafont $^{1}$ \\
\hline A-003 & 363,00 & 1.815 .000 & & Ribeirão do Tronco & Lafont $^{1}$ \\
\hline A-004 & 115,00 & 575.000 & & Ribeirão do Tronco & Lafont $^{1}$ \\
\hline A-005 & 100,00 & 500.000 & & Ribeirão do Tronco & Lafont $^{1}$ \\
\hline A- 028 & 100,00 & 500.000 & & Ribeirão do Tronco & Lafont $^{1}$ \\
\hline A-030 & $2.000,00$ & 10.000 .000 & $\begin{array}{l}\text { Rio Pequeno e } \\
\text { Sítio do Limoeiro }\end{array}$ & Lafont $^{2}$ & Lafont $^{1}$ \\
\hline A-035 & 110,00 & 550.000 & & Ribeirão do Tronco & Lafont $^{1}$ \\
\hline A-050 & 179,00 & 895.000 & $\begin{array}{l}\text { Rio Pequeno e } \\
\text { Sítio do Limoeiro }\end{array}$ & Lafont $^{2}$ & Lafont $^{1}$ \\
\hline A-051 & 90,00 & 450.000 & $\begin{array}{l}\text { Rio Pequeno e } \\
\text { Sítio do Limoeiro }\end{array}$ & Lafont $^{2}$ & Lafont $^{1}$ \\
\hline A-052 & $1.400,00$ & 7.000 .000 & $\begin{array}{l}\text { Rio Pequeno e } \\
\text { Sítio do Limoeiro }\end{array}$ & Lafont $^{2}$ & Lafont $^{1}$ \\
\hline A-092 & 183,81 & 919.050 & & Ribeirão do Tronco & Lafont $^{1}$ \\
\hline A-093 & 100,00 & 500.000 & $\begin{array}{l}\text { Rio Pequeno e } \\
\text { Sítio do Limoeiro }\end{array}$ & Lafont $^{2}$ & Lafont $^{1}$ \\
\hline A-109 & $1.150,00$ & 5.750 .000 & Rio Pequeno & Lafont $^{2}$ & Lafont $^{1}$ \\
\hline
\end{tabular}

Total

$\mathbf{5 . 9 3 0 , 8 1} \quad \mathbf{2 9 . 6 5 4 . 0 5 0}$

Legenda: Lafont ${ }^{1}$ - título dominial original, com área em Antonina. Lafont ${ }^{2}$ - título dominial em duplicata, no Município de Antonina. 
Tabela 5. Projetos de reflorestamento implantados em áreas de superposição de títulos dominiais, Município de Guaraqueçaba, Estado do Paraná, BRASIL - Lei n. 5.106

\begin{tabular}{|c|c|c|c|c|c|}
\hline $\begin{array}{c}\text { Pesquisa } \\
\text { N }^{\mathbf{0}} \\
\end{array}$ & Área (ha) & $\begin{array}{l}\mathbf{N}^{\circ} \text { de } \\
\text { Árvores }\end{array}$ & $\begin{array}{c}\text { Denominação } \\
\text { da área }\end{array}$ & $\begin{array}{c}\text { Gleba de } \\
\text { origem }\end{array}$ & Gleba em sobreposição \\
\hline A-025 & 426,60 & 2.133 .000 & & Fronteira & Cia. União Colonial $^{1}$ \\
\hline A-048 & $4.310,00$ & 21.550 .000 & & $\begin{array}{l}\text { Cia. União } \\
\text { Colonial }^{1}\end{array}$ & \\
\hline A-104 & 230,95 & 1.154 .750 & Serra Negra & & Cia. União Colonial ${ }^{1}$ \\
\hline A-106 & 857,00 & 4.235 .000 & Serra Negra & & Cia. União Colonial ${ }^{1}$ \\
\hline A-107 & 342,00 & 1.710 .000 & Serra Negra & & Cia. União Colonial ${ }^{1}$ \\
\hline A-108 & $3.300,00$ & 16.500 .000 & & Fronteira & Cia. União Colonial ${ }^{1}$ \\
\hline A-110 & $1.380,00$ & 6.900 .000 & Rio Pequeno & Lafont $^{3}$ & Lafont $^{1}$ \\
\hline A-111 & 250,00 & 1.250 .000 & Serra Negra & & Cia. União Colonial ${ }^{1}$ \\
\hline A-113 & 354,00 & 1.770 .000 & & Fronteira & Cia. União Colonial ${ }^{1}$ \\
\hline A-114 & 100,00 & 500.000 & & Fronteira & Cia. União Colonial ${ }^{1}$ \\
\hline A-115 & 100,00 & 500.000 & & Fronteira & Cia. União Colonial ${ }^{1}$ \\
\hline A-116 & 300,00 & 1.500 .000 & & Fronteira & Cia. União Colonial ${ }^{1}$ \\
\hline A-117 & 525,00 & 2.625 .000 & & Fronteira & Cia. União Colonial ${ }^{1}$ \\
\hline A-118 & $4.203,50$ & 21.017 .500 & & Fronteira & Cia. União Colonial ${ }^{1}$ \\
\hline A-119 & 188,00 & 940.000 & & Fronteira & Cia. União Colonial ${ }^{1}$ \\
\hline A-124 & 528,00 & 2.640 .000 & Rio Pequeno & Lafont $^{3}$ & \\
\hline A-126 & $1.174,00$ & 5.870 .000 & Rio Pequeno & Lafont $^{3}$ & \\
\hline A-127 & $1.644,00$ & 8.220 .000 & & Fronteira & Cia. União Colonial ${ }^{1}$ \\
\hline A-129 & $1.000,00$ & 5.000 .000 & & Fronteira & Cia. União Colonial ${ }^{1}$ \\
\hline A-131 & $1.229,00$ & 6.146 .000 & & $\begin{array}{l}\text { Cia. União } \\
\text { Colonial }^{1}\end{array}$ & \\
\hline A-138 & $1.164,90$ & 5.824 .500 & Pederneiras & & Cia. União Colonial ${ }^{1}$ \\
\hline A-151 & 715,92 & 3.579 .600 & $\begin{array}{l}\text { Rio Pequeno e } \\
\text { Tapera Grande }\end{array}$ & Lafont $^{3}$ & Lafont $^{1}$ \\
\hline A-166 & $1.590,00$ & 7.950 .000 & & Fronteira & Cia. União Colonial ${ }^{1}$ \\
\hline Total & $25.912,87$ & 129.515 .350 & & & \\
\hline
\end{tabular}

Legenda: Cia. União Colonial ${ }^{1}$ - área adquirida pelo Estado do Paraná pelo Título no 28, de 19.04.1920, de 50.000ha, localizada em Serra Negra, Município de Guaraqueçaba, Estado do Paraná, sem definição de localização e confrontantes. Lafont $^{1}$ - título dominial original, com área em Antonina. Lafont ${ }^{3}$ - título dominial em triplicata, extrapolando para o Município de Guaraqueçaba.

\section{Abordagem sobre os manejos sustentados}

Nos levantamentos feitos neste trabalho constataram-se as mesmas imperfeições já verificadas nos planos de reflorestamento com incentivos realizados no passado. A imprecisão nas análises documentais tem colocado em risco tais políticas de incentivos ao reflorestamento e ao seu manejo. A possibilidade de manejos sustentados é real, porém é preciso que se avance na redução destas falhas.

A simples introdução do georreferenciamento pode não ser suficiente para evitar as sobreposições, pois a área pode ser objeto de sobreposição de titularidade, ou mesmo contendo vícios de origem.
Cabe ressaltar que, apesar da introdução da Resolução Conjunto IBAMA/SEMA-PR Nº 001/ 2002 (BRASIL, 2002), com o objetivo de priorização e conservação da biodiversidade do ecossistema, na exploração de palmito (Euterpe edulis Martius) encontra-se vinculada a apresentação do plano de manejo florestal sustentado nas propriedades e posses rurais superiores a 50ha, e cuja autorização dependa da avaliação da Câmara Técnica Florestal composta por integrantes do Instituto Ambiental do Paraná - IAP e do Instituto Brasileiro do Meio Ambiente e dos Recursos Naturais Renováveis IBAMA. Na análise documental persistem as mesmas falhas, que áreas originalmente reflorestadas 
com incentivos, podem ser alvos de extração de palmitos (Euterpe edulis Martius), através de planos de manejo em nome de terceiros, utilizando os títulos dominiais em sobreposição, que levam a degradação da Mata Atlântica, com a anuência dos órgãos de fiscalização oficial.

Os vícios de caráter dominial e possessório perpetuam-se, considerando as aquisições das Áreas de Unidades de Conservação pelo Poder Público, da apreciação por parte do IBAMA de Reserva Particular do Patrimônio Natural - RPPN, na Certificação Florestal (FSC), nos projetos ambientais como os de comercialização de carbono $\left(\mathrm{CO}_{2}\right)$.

Sugere-se que, além da adoção de novas técnicas de fiscalização de campo, haja uma capacitação das pessoas dos órgãos envolvidos, visando a redução dos potenciais vícios de titularidade das áreas incentivadas, dentro da realidade registral do Brasil.

\section{Conclusões}

$\mathrm{Na}$ amostragem aleatória dos projetos de reflorestamento incentivados pela Lei n. 5.106 da Comarca de Antonina, a totalidade dos imóveis é viciada, contendo litígios possessórios e sobreposição de títulos dominiais desde 1920;

A ineficiência na análise sobre a legitimidade e legalidade dos títulos dominiais pode ser uma das razões fundamentais do insucesso dos empreendimentos de reflorestamento de palmito (Euterpe edulis Martius) avaliado.

A técnica de análise dominial das áreas proponentes pode ser uma ferramenta adequada para reduzir a possibilidade de fraudes e de insucessos nos projetos de reflorestamento e de outros incentivos.

\section{Agradecimentos}

Ao Instituto Brasileiro do Meio Ambiente e dos Recursos Naturais Renováveis - IBAMA, Superintendência do Paraná, pela concessão parcial dos dados da pesquisa.

Ao Juízo de Direito da Vara Cível da Comarca de Antonina, Estado do Paraná, pela permissão e consulta dos processos judiciais de ações de naturezas diversas existentes na Vara, abrangendo os Municípios de Antonina e Guaraqueçaba.

\section{Referências}

BACHA, C. J. C. A. Análise custo-benefício dos programas federais de incentivos ao reflorestamento no Brasil. In: CONGRESSO BRASILEIRO DE ECONOMIA E SOCIOLOGIA RURAL, 33., 1995, Curitiba. Anais... Curitiba: SOBER, 1995. p.1.007-1.030.

BRASIL, Resolução Conjunta IBAMA/SEMA-PR N $N^{o} 001 /$ 2002, de 23.10.2002.

LOPES, I. V.; BASTOS FILHO, G. S.; BILLER, D.; BALE, M. (Org.) Gestão ambiental no Brasil: experiências e sucessos. 3.ed. Rio de Janeiro: FGV, 2000.

NOGUEIRA, J. N. Palmito: produção, pré-processamento e transformação agroindustrial. São Paulo: Secretaria da Indústria e Comércio, Ciência e Tecnologia do Governo do Estado de São Paulo, 1977. p.66. (Série Extensão Agroindustrial, v.6)..

YEE, Z. C. Manual prático da investigação dominial. Curitiba: Juruá, 2000.

. A origem de superposição dos títulos dominiais no Estado do Paraná. Verba Iuris: Revista de Estudos Jurídicos da PUCPR, Curitiba, v.3, n.2, p.59-63, mar.2001.

Perícias indenizatórias \& de desapropriação: aspectos processuais e casos práticos. Curitiba: Juruá, 2003.

YEE, Z. C.; RALISCH, R. Avaliação da política pública na gestão de recursos naturais renováveis: uma abordagem florestal. Semina: Ciências Agrárias, Londrina, v.26, n.4, p.501-506, out./dez. 2005. 